COMPORTAMENTO ORGANIZACIONAL 


\title{
GLAMOUR OU TRABALHO ÁRDUO: SOCIALIZAÇÃO PROFISSIONAL DAS BLOGUEIRAS
}

\author{
GLAMOR OR WORK ARRIVAL: \\ PROFESSIONAL SOCIALIZATION OF BLOGS
}

Rafaela de Almeida Araújo

Universidade Federal do Ceará

Serafim Firmo de Souza Ferraz

Universidade Federal do Ceará

Tereza Cristina Batista de Lima

Universidade Federal do Ceará

Data de submissão: 07 set. 20 | 8. Data de aprovação:

02 fev. 2019. Sistema de avaliação: Double blind review.

Universidade FUMEC / FACE. Prof. Dr. Henrique Cordeiro

Martins. Prof. Dr. Cid Gonçalves Filho.

Luis Eduardo Brandão Paiva

Universidade Federal do Ceará

\section{RESUMO}

Este estudo objetiva investigar como acontece a socialização profissional de blogueiras, baseando-se na teoria de Hughes (1958) e Dubar (2005). Esta pesquisa é caracterizada como qualitativa, descritiva, realizada por meio entrevistas estruturadas junto a 15 blogueiras. Os resultados apontam que 0 interesse se deu por acompanharem outros blogs como leitora ou a partir da necessidade de escrever sobre assuntos do seu interesse, a inserção se deu pela aquisição de habilidades educacionais, de indicação de alguém ou por divulgação nas redes sociais. $O$ modelo de profissão construído pela idealização de uma profissão fácil e glamourosa, em oposição a uma atividade real, que exige muito trabalho para conquistar público e conseguir parcerias, com reconhecimento não imediato e, de início, possui remuneração baixa. Por fim, reconheceu-se que no trabalho desenvolvido com blogs as ajudou na orientação profissional, com o equilíbrio da imagem público-privado e trazendo uma nova percepção sobre si.

PALAVRAS-CHAVE

Socialização Profissional. Identidade Profissional. Carreira. Blogs. Mídias Sociais. 


\section{ABSTRACT}

This study aims to investigate how the professional socialization of bloggers happens, based on the theory of Hughes (1958) and Dubar (2005). It was sought to investigate the motivations and forms of professional insertion, to verify how the profession is perceived, as an idealized model and real model of profession, and to explore the perceptions about career possibilities. This research is characterized as qualitative, descriptive, performed with structured interviews with 15 bloggers. The results indicate the interest came either from following other blogs simply as a reader or from the necessity to write on subjects of their interest. The insertion came throught acquisition of educational skills, indication of someone or dissemination in social networks. The model of profession idealized of an easy and glamorous profession, as opposed to a real activity that requires hard work to gain public and obtain partnerships without immediate recognition and an initial low remuneration. Finally, it is recognized the work developed with blogs helped them in professional orientation, with the balance of public-private image, bringing a new perception about themselves.

\section{KEYWORDS}

Professional Socialization. Professional Identity. Career. Blogs. Social Media.

\section{INTRODUÇÃO}

Os consumidores se destacam nas mídias sociais por publicarem opiniões sobre empresas e produtos, e isto acaba por influenciar e intermediar o contato direto das empresas com os seus clientes. Diante disso, e ainda com o interesse que as empresas passaram a ter nesses consumidores (considerados influenciadores) - os quais proporcionam a divulgação de seus produtos - passou-se a pagar para que aquela opinião fosse disponibilizada nas mídias sociais de um influenciador (CHAU; XU, 20 I2; CRESCITELLI; TAGAWA, 20I5; PEDRON et al., 20I5), tais como blogs, Instagram, Facebook, Twitter, entre outros (BURGESS; BRUNS, 20I8).

Para que uma atividade se profissionalize, torna-se pertinente destacar a aprendizagem, que direciona a prática e a experiência direta da realização das atividades no contato diário com as atividades do ofício, ligadas a uma formação inicial com possibilidades de projetar uma carreira relacionada a alguma especialidade, com a progressão regular, o aprimoramento técnico e a longevidade da atividade (DUBAR, 2005). Diante dessa abordagem, nesta pesquisa, as atividades realizadas inerentes ao trabalho com blogs são caracterizadas como "ofício".

Verifica-se, portanto, um aumento nas pesquisas relacionadas às mídias sociais, configurando os blogs como uma ferramenta estratégica das empresas que são formadores opiniões (CHAU; XU, 20I2; CRESCITELLI;TAGAWA, 20 I5; SILVA et al., 20I5). Entretanto, estudos na área sobre a profissionalização de atividades ainda não formalizadas, a exemplo de blogueiros(as), pouco têm sido realizados, mesmo com o 
aumento dessa profissão. Ademais, tendo em vista que ainda é uma profissão emergente, torna-se relevante compreender como esse elemento influencia na identidade dos profissionais dos blogs, a exemplo das blogueiras. Considerando também as discussões acerca de gênero, enfatiza-se que a escolha por mulheres se deu devido ao fato de que elas utilizam a ferramenta web blogs na sua forma original, ou seja, como diários eletrônicos, sendo em maior número quando comparadas com os homens (HERRING et al., 2004).

Este tema se torna relevante no âmbito profissional e acadêmico, em virtude do contexto global das mídias sociais e das relações de trabalho em que os blogs estão inseridos, transformando-se uma ferramenta de informação e publicidade online segmentada (CHAU; XU, 20I2, CRESClTELLI; TAGAWA, 20I5; MCQUARRIE; MILLER; PHILLIPS, 20I2; SILVA et al., 20I5), por meio da qual surgiu uma nova modalidade de atividade rentável. Isso possibilita o despertar de investigações empíricas nessa área do conhecimento, com o intuito de compreender como surgiu, acontece e como tem afetado as atuais formas de trabalho a distância. Diante dessas abordagens, surge $o$ seguinte questionamento para este estudo: como ocorre o processo de socialização profissional das mulheres que trabalham com blogs?

Esta pesquisa tem como objetivo geral, portanto, investigar como acontece a socialização profissional de blogueiras. Para tanto, baseando-se na teoria de Hughes (1958; 2015) e Dubar (2005), modelo no qual se baseia nos estereótipos que os indivíduos têm sobre a profissão, como acontece sua inserção e quais as mudanças percebidas tanto sobre a profissão e sobre a identida- de profissional. Diante disso, destacam-se os seguintes objetivos específicos: (i) investigar a motivação e a inserção profissional em blogs; (ii) verificar como a profissão é percebida por aquelas que nela se inserem, enquanto modelo idealizado e modelo real de profissão; e (iii) explorar as possibilidades de carreira e as mudanças de identidade profissional neste ofício.

Esta investigação busca aprofundar a discussão sobre como ocorre o surgimento de novas profissões (como a profissão "blogueiras"). Ademais, tenta suplantar a lacuna teórico-empírica sobre a socialização profissional das blogueiras, considerada escassa ou quase inexistente, dado que os estudos realizados sobre socialização profissional, em sua maioria, são realizados em profissões já formalizadas no mercado, como os da área da saúde, a exemplo da medicina, enfermagem, fisioterapia, entre outras (HUGHES, 1958; PRICE, 2009; SHINYASHIKI et al., 2006; ZARSHENAS et al., 20I4).

\section{FUNDAMENTAÇÃO TEÓRICA Identidade profissional}

A identidade é construída e reconstruída com as experiências socioculturais durante a vida das pessoas (BROWN, 20 I4; DUBAR, 2005; ELIOT; TURNS, 20I I; FROST; REGEHR, 20I3; SANTOS et al., 20I8). As relações sociais e o processo de aprendizagem proporcionam meios nos quais são extraídos e incorporados discursos, normas, práticas e processos existentes para dar sentido as suas próprias experiências de vidas por meio do reconhecimento do outro e da absorção de certos valores e crenças que julgam inconsciente ou conscientemente adequadas para si (DUBAR, 2005; FROST; REGEHR, 20 I3). 
O trabalho pode ser definido como "uma atividade de caráter produtivo, realizada por pessoas, para assim obterem alguma remuneração e/ou para contribuírem com sua própria subsistência" (BERNAL, 20I0; p. 14). Tomando o trabalho como ponto de partida, destacam-se as profissões, formalmente constituídas, que são geralmente vistas de forma prestigiada e ligadas a um saber provido pelo o seu diploma. Em contrapartida, os ofícios estão ligados a uma formação inicial da atividade, na qual se objetiva uma carreira ligada a essa especialidade e que ocasiona uma progressão ligada à antiguidade e ao aperfeiçoamento técnico dessa especialidade (DUBAR, 2005; HUGHES, I958; 2015). Diante destes conceitos, é possível afirmar que o trabalho com blogs, por ainda não ser formalizado, pode ser considerado um ofício.

O trabalho de uma pessoa é essencial para a sua identidade social, de seu "eu". A escolha da profissão ocorre a partir de influências do grupo ao qual o indivíduo pertence, como o ambiente familiar ou outro que ele deseja pertencer (DUBAR, 2005; HUGHES, I958; 20I5; SPUDEIT; CUNHA, 2016; SLAY; SMITH, 20II; TADIM et al., 20I5). A identidade do trabalhador para si mesmo ocorre no local de trabalho, perpassando pela vivência acadêmica e escolar e privilegiando a aprendizagem e as experiências profissionais, processos esses que contribuem para um maior entendimento de si (DUBAR, 2005; HUGHES, 1958; 20I5; SPUDEIT; CUNHA, 2016; TADIM et al., 20I5). De acordo com Trede (20I2), para que aconteça a formação da identidade profissional, é necessário que os indivíduos tomem consciência do que mais importa na prática, quais valores e interesses moldam a tomada de decisão.
A identidade profissional é percebida como o autoconceito que o profissional tem de si mesmo e de seu trabalho no contexto de suas áreas e como ele adquire status entre os seus colegas de profissão. Portanto, por definição, é uma identidade que o profissional internaliza, orientando suas ações e decisões externas na profissão, que incluem as suas decisões no ambiente de trabalho com aquisição de habilidades, qualidades, comportamentos, valores e padrões da profissão (BROWNELL; TANNER, 20I2; DUBAR, 2005; FROST; REGEHR, 20I3; JACKSON, 20I7; SLAY; SMITH, 20II). As identidades podem ser moldadas no ambiente de trabalho na medida em que as carreiras dos indivíduos progridem (PRATT; ROCKMANN; KAUFMANN, 2006).

Conforme o exposto, a identidade é construída por meio do ato de se socializar, a partir do momento em que se assume dentro de um enquadramento em grupos de referência, com o intuito de se apoderar de suas atitudes (BIANCO; COLBARI; SILVA NETO, 20I0; DUBAR, 2005; HUGHES 1958, 20 I5;TREDE, 20 I2; SPUDEIT; CUNHA, 2016).

Observa-se que a identidade profissional é um processo reflexivo, construído com base em aprendizagens técnicas, teóricas e vivências práticas oriundas da profissão. Sendo assim, tem-se como relevância para investigações sobre a socialização profissional ampliar a compreensão da socialização de trabalho que molda a identidade do indivíduo.

\section{Socialização profissional}

A socialização profissional é um processo que se inicia na absorção de valores, crenças e concepções de uma cultura que, muitas vezes, se origina na profissão 
(DUBAR, 2005; HUGHES, 1958; 20I5; RODRIGUES; PAES; SOUZA NETO, 20I5; SANTOS et al., 2018; SPUDEIT; CUNHA, 2016), permitindo que o aprendiz adquira conceitos do ofício, tais como a maneira de se portar, grau de tolerância do grupo profissional para se estabelecer diferenças e divergências, habilidades e expectativas profissionais, hierarquização de cargos, entre outros (DUBAR, 2005; FREITAS, 2002; HUGHES, 1958; 20I5). Esse processo não acontece de forma linear, pois se deve considerar histórico, expectativas e projetos do profissional quanto ao grupo de trabalho (DUBAR, 2005; FREITAS, 2002; HUGHES, 1958; 20 I5; SCHEIN, 1996).

Ao iniciar um novo trabalho, ocorre no indivíduo um confronto entre os estereótipos que ele possui sobre a profissão versus a realidade que o profissional encontra durante a prática do ofício. Nessa fase há um choque para o indivíduo entre o modelo que ele idealiza e o modelo vivenciado na realidade da profissão (HUGHES, 1958; 2015). Em seguida, os estereótipos da cultura leiga são abandonos ou recalcados pelos profissionais (HUGHES, 1958; 20I5), em que, a partir das novas habilidades adquiridas por meio das tarefas desempenhadas pelo indivíduo (DUBAR, 2005; SERON et al., 2006), ocorre a conversão final da dualidade entre o modelo idealizado e as 'normas práticas' do ofício, representando o ajuste da concepção da profissão no profissional (DUBAR, 2005; HUGHES, 1958; SANTOS et al., 2018; SCHEIN, 1996). Essa interação pode ocorrer por toda a vida (CORRÊA JUNIOR; SOUZA NETO; IZA, 20I 7; DUBAR, 2005; HUGHES, 1958), mas parece ser autoconsciente, desconfortável e, talvez, mais profundamente inconsciente, no período de aprendizagem e iniciação da profissão (DUBAR, 2005; HUGHES, 1958; 20I5).

Depois de lidar com esse confronto entre os estereótipos e a realidade, o profissional se ajusta ao que imaginava e a realidade vivenciada durante a profissão, iniciando, a partir desse momento, a construção de sua carreira (HUGHES, 1958; 20I5), com a internalização e o desenvolvimento da identidade profissional (ZARSHENAS et al., 20I4). Por fim, identificam-se as oportunidades de carreira, fases significativas e a sequência em que acontecem (HUGHES, 1958; 2015).

$\mathrm{Na}$ medida em que ocorre a progressão na carreira, o indivíduo obtém novos conceitos sobre si mesmo. Esses conceitos se desenvolvem em virtude de concepções adquiridas desde o início de suas experiências de educação e juventude. Contudo, esse novo conceito sobre si só amadurece após uma satisfatória experiência profissional que possibilita o conhecimento de suas aptidões, seus objetivos e seus valores (CORRÊA JUNIOR; SOUZA NETO; IZA, 20 I7; DUBAR, 2005; HUGHES, I958; 20I5). O ajuste da concepção em si se refere à apropriação por parte do trabalhador de sua identidade que está sendo construída, a partir da consciência de suas capacidades físicas, mentais e pessoais, em ajuste com as possibilidades de carreira (DUBAR, 2005; PRICE, 2009).

As mudanças ocorridas são acompanhadas de anseios pelos profissionais, uma vez que, com a execução de novas atividades, existe a possibilidade de perder alguma habilidade. Esses pontos são essenciais para a ponderação na carreira e para o crescimento e o desenvolvimento da identidade profissional (HUGHES, 1958; 2015; SCHEIN, 1996). Essas mudanças de iden- 
tidade podem ocorrer tanto de forma suave, quando acontece a percepção de uma identidade profissional; ou de forma mais dramática, envolvendo mudanças na identidade profissional. A construção da identidade profissional pode ocorrer por meio da compreensão das mudanças do trabalho que se executa durante a carreira, no qual as mudanças na identidade estão entrelaçadas com as mudanças no trabalho (PRATT; ROCKMANN; KAUFMANN, 2006).

Dessa forma, pode-se enfatizar que dentro da socialização profissional está contido o processo da formação de identidade do trabalhador, bem como a forma como este interage com os outros profissionais, as suas tarefas, mudanças e possibilidades de progressão de carreira, culminando na formação de uma identidade profissional.

\section{Trabalho e mídias sociais - blogs}

As mídias sociais surgiram como ferramentas de criação de conteúdo e divulgação de baixo custo. Pessoas compartilham aspectos de suas vidas e interagem mediante os diversos recursos de imagem, som, texto e vídeo, o que possibilitou uma alternativa para o composto tradicional de comunicação, publicidade e, consequentemente, das relações de trabalho (LIMA et al., 20I3). Em essência, os blogs são caracterizados como mídias sociais, pois possibilitam essa interação social e transmitem conteúdo de informação (TORRES, 2009; MCQUARRIE; MILLER; PHILLIPS, 2012; NASCIMENTO; RIBEIRO; CAMPOS, 2016). De modo geral, as resenhas e os conteúdos abordados nos blogs têm por característica incitar o consumo principalmente de moda, comida e decoração da casa (MCQUARRIE; MILLER; PHILLIPS, 20I2).

Os blogs se transformaram em intermediários entre as empresas e os consu- midores (CHAU; XU, 20I2; NOGUEIRA; FERREIRA;ARRUDA FILHO, 20I8), agindo como uma ferramenta de divulgação de informações (CHAU; XU, 20I2; PEDRON et al., 20I5). Evidencia-se que essa forma de publicidade pode ajudar as empresas a identificar os grupos de clientes direcionados para os seus produtos e serviços, e isto permite realizar um marketing de destino ou de seguimento, que foca nos influenciadores com os quais os seus consumidores se identificam (CHAU; XU, 20I2; OLIVEIRA; MOREIRA NETO, 2016).

Os blogs podem ser distintos e classificados em dois tipos: profissionais e pessoais. A diferença principal é que, nos blogs pessoais, quem o escreve não apresenta finalidade comercial, apenas a pretensão de escrever e criar relacionamentos. Os blogueiros profissionais têm centenas de outros blogueiros pessoais que consomem seus conteúdos como leitores (TORRES, 2009). Essa interação entre blogs - profissionais e pessoais - e marcas patrocinadoras formam redes sociais digitais de relacionamentos diante de visitantes e patrocinadores (CASTRO; SANTOS, 20I5). Para Nogueira, Ferreira e Arruda Filho (20l8), a profissão blogueira pode ser considerada rentável e desejada, sendo comparada, muitas vezes, com celebridades.

Nas relações sociais e de trabalho que ocorrem nos blogs são compartilhados interesses e opiniões em comum, dado que os blogueiros interagem mutuamente por meio de indicações de publicações em outros blogs. "Com isso, os blogs tornaram um importante tipo de mídia, potencialmente úteis para vários tipos de estratégias de negócios" (CHAU; XU, 20 I2, p. 189, livre tradução). Essa relação pode ser percebida mediante o modelo apresentado na Figura I. 


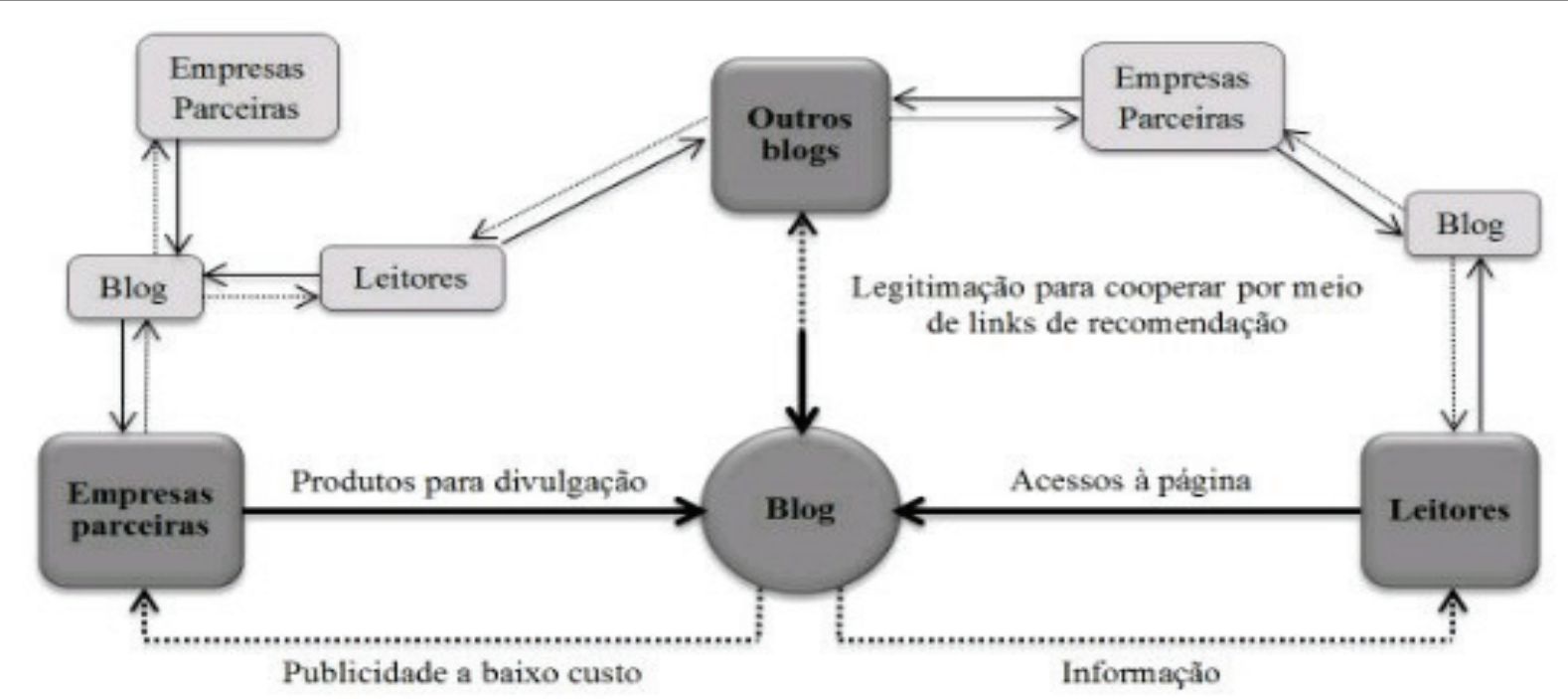

FIGURA 1 - Relações entre blogs, leitores e empresas parceiras

Fonte: adaptada de Castro e Santos (2015).

A ascensão dos blogueiros como influenciadores de consumo ocorre por meio de cidadãos comuns, com opiniões interessantes ou habilidades específicas, que podem ajudar os demais usuários a resolverem qualquer tipo de problema. Essas pessoas passaram a chamar a atenção de outros indivíduos e, progressivamente, ganhar importância no mundo digital. Muitos desses influenciadores recomendam e estimulam, mas também reprovam produtos e/ou serviços (CRESCITELLI; TAGAWA, 20I5). Esse processo é comum em resenhas de maquiagem e moda, por exemplo (CRESCITELLI; TAGAWA, 20I5; NASCIMENTO; RIBEIRO; CAMPOS, 2016). Além disso, apesar de diversos segmentos terem passado a ser explorados com os avanços da internet, a moda foi um dos que mais se adequou - sendo uma das categorias mais buscadas e seguidas pelos consumidores na internet (BORGES, 2016).

Para se atrair leitores e influenciar opiniões é necessário muito mais qualidade de ideias e escrita do que de credenciais formais (HERRING et al., 2004). Isso foi comprovado no estudo de Lasater-Wille (20l8), com chefs de cozinha, na qual a autora verificou que mais importante que os traços formais eram os de personalidade.

No que se refere à validade dessas informações, as quais estão disponibilizadas nos blogs, a credibilidade da notícia fica delegada ao consumidor daquela informação, já que nesses meios não há controle ou propriedade. Quem produz e julga o que merece ser lido e divulgado é quem o escreve, o que antes somente era visto nas mídias tradicionais, como o rádio e a televisão (MCQUARRIE; MILLER; PHILLIPS, 20I2;TORRES, 2009).

\section{METODOLOGIA}

Essa pesquisa é caracterizada como qualitativa, de natureza descritiva, pois busca descrever características de uma determinada população, fenômeno e estabelece relações entre as variáveis (COLLIS; HUSSEY, 2005) da socialização profissional de blogueiras.

Adotou-se o modelo de Hughes (1958), adaptado por Dubar (2005), que buscou investigar a motivação e a inserção profis- 
sional em blogs; verificar como a profissão é percebida por aquelas que nela se inserem, enquanto modelo idealizado e modelo real de profissão; e explorar as possibilidades de carreira e as mudanças de identidade neste ofício.

O universo pesquisado é composto por mulheres blogueiras. Esta escolha se deu devido à comprovação de que as blogueiras são as precursoras dos blogs e, em sua maioria, jovens que utilizam os web blogs como diários eletrônicos (HERRING et al., 2004). Além disso, optou-se realizar esta investigação somente com as mulheres pela representatividade feminina no mercado de trabalho e nas novas profissões emergentes.

As blogueiras investigadas utilizavam pelo menos duas mídias sociais - por mídias sociais entende-se blog, Facebook, Instagram e YouTube - para a divulgação de seu trabalho. A escolha das entrevistadas foi por conveniência em pesquisa via Google, com base nas quantidades de seguidores que elas tinham, sendo estabelecida uma quantidade mínima de 5.000 (cinco mil) seguidores em pelo menos uma das mídias sociais. Foram considerados apenas blogs que comportassem o seu próprio domínio, tendose como registro o ponto com (.com) ou ponto com ponto br (.com.br).Além disso, somente foram incluídas nas pesquisas blogueiras profissionais (TORRES, 2009), sendo necessário que já houvessem firmado parceria com marcas, o que foi constatado por publicações com publicidade. Não se distinguiram os conteúdos abordados nos blogs, pois, assim como a literatura afirma, mesmo nos blogs segmentados são abordados diversos assuntos.

A estratégia adotada foi entrar em contato com as blogueiras, partindo-se de suas mídias sociais. Apesar do interesse inicial de algumas blogueiras em participar da pesquisa, houve uma dificuldade para que ocorresse o contato direto com as blogueiras. As entrevistas foram realizadas pessoalmente e por e-mail, em que aconteceram adaptações para que as perguntas ficassem bem explicadas e tivessem o mínimo de dúvidas (ou interpretações ambíguas), levando-se em conta uma entrevista estruturada (COLLIS; HUSSEY, 2005).

O período de aplicação das entrevistas ocorreu entre agosto e outubro de 2016, e buscou incluir, no mínimo, uma entrevistada de cada uma das cinco regiões do país, não tendo sido encontradas blogueiras da Região Norte dispostas a participar da pesquisa. Foram entrevistadas quinze blogueiras, sendo quatro do Nordeste, oito do Sudeste, duas do Sul e uma do Centro -Oeste. Os blogs pesquisados abordam diversos conteúdos, a exemplo de moda, maquiagem, comportamento, cabelos, livros, viagens, estilo de vida, entre outros. As participantes desta pesquisa foram identificadas sob o título de "blogueira", seguido pela numeração equivalente à ordem das entrevistas, compreendida entre os números $0 \mathrm{I}$ e I5. O perfil das entrevistadas pode ser observado no Quadro I.

Para o tratamento dos dados, utilizouse o método da análise de conteúdo, por ser um procedimento sistemático e objetivo para descrever, por meio de códigos, o conteúdo presente nas mensagens (BARDIN, 2008). Adotou-se o software ATLAS.ti 7 por auxiliar na codificação dos dados, apontando tendências e padrões em análises qualitativas. A visualização dos resultados de cada categoria é realizada com auxílio da ferramenta Network View desse software. 
QUADRO 1 - Perfil das blogueiras entrevistadas

\begin{tabular}{|l|l|l|l|l|}
\hline Entrevistada & Idade & $\begin{array}{l}\text { Tempo de atuação } \\
\text { como blogueira } \\
\text { profissional }\end{array}$ & Formação Profissional & Cidade/estado \\
\hline Blogueira 01 & 22 & 1 ano e 7 meses & Graduada em Jornalismo, Mestranda em mídia e cotidiano & Niterói/RJ \\
\hline Blogueira 02 & 24 & 6 anos & $\begin{array}{l}\text { Graduada em Design Gráfico, cursando MBA em Gestão } \\
\text { estratégica de Marketing }\end{array}$ & Fortaleza/CE \\
\hline Blogueira 03 & 29 & 7 anos & Superior Incompleto em Psicologia & Uberlândia /MG \\
\hline Blogueira 04 & 28 & 1 ano e 6 meses & Graduada, Mestre e Doutoranda em Sociologia & Fortaleza/CE \\
\hline Blogueira 05 & 20 & 6 anos & Graduanda em Direito & União da Vitória/PR \\
\hline Blogueira 06 & 31 & 5 anos & Graduada em Administração de RH e Rede de computadores & São Paulo/SP \\
\hline Blogueira 07 & 25 & 5 anos e 7 meses & Graduada em Administração & Maringá/PR \\
\hline Blogueira 08 & 25 & 3 anos & Graduada em Artes Visuais & São Paulo/SP \\
\hline Blogueira 09 & 23 & 3 anos & Graduada em Psicologia & Salvador/BA \\
\hline Blogueira 10 & 25 & 3 anos & Graduada em Comunicação social Rádio e Tv & Baulo/SP \\
\hline Blogueira 11 & 27 & 2 anos e 9 meses & Graduada/DF em Ciências Contábeis & São Carlos/SP \\
\hline Blogueira 12 & 28 & 1 ano & Graduada em Biomedicina & São Paulo/SP \\
\hline Blogueira 13 & 27 & 6 meses & Graduada em Nutrição e Graduanda em Letras & Poços de Caldas/MG \\
\hline Blogueira 14 & 24 & 2 anos & Graduada em Gastronomia, especialista em Garde Manger & Fortaleza/CE \\
\hline Blogueira 15 & 24 & 4 anos e 6 meses & $\begin{array}{l}\text { Graduada em Publicidade e propaganda, Cursando MBA } \\
\text { em Varejo e marketing }\end{array}$ & \\
\hline
\end{tabular}

Fonte: dados da pesquisa.

\section{APRESENTAÇÃO E SÍNTESE DOS RESULTADOS}

Com a finalidade de discutir os resultados da pesquisa, apresentam-se, a seguir, a motivação e ingresso na profissão, modelos da profissão e percepções sobre a profissão, além das possibilidades de carreira conforme a segmentação dos objetivos específicos da pesquisa.

\section{Motivação e ingresso na profissão}

Para compreender como acontece a socialização profissional de blogueiras, investigou-se, primeiramente, o que motivou as entrevistadas a criarem seus blogs e como aconteceu a profissionalização de seus blogs. Os interesses são examinados a partir da ideia que a entrevistada tinha sobre essa atividade de trabalho antes de iniciá-la, que é considerada a cultura leiga. Já a inserção nesta atividade faz parte de como ela se inseriu no mercado de trabalho, assim como apresentado na teoria de Hughes (1958;
20I5) e adaptada por Dubar (2005). Na Figura 2 estão representados os principais achados das motivações das blogueiras para que criassem seus blogs, bem como a forma que elas se inseriram nesse meio.

Constatou-se, nas motivações, que as entrevistadas criaram seus blogs a partir de interesses que tinham em acompanhar outros blogs ou por sentirem necessidade de compartilhar suas ideias. Assim como a blogueira 04 afirmou:"Primeiro que eu já consumia conteúdo de blogs, sempre gostei muito do tema, de moda, de maquiagem... todo meu tempo livre praticamente era vendo tutorial de maquiagem, vendo tutorial de cabelo, vendo produtos, coisas sobre moda".

Onze blogueiras reforçaram que iniciaram seus blogs porque sentiam a necessidade de compartilhar suas ideias ou mesmo para desabafar sobre determinados assuntos; sendo assim, este parece ter sido a principal motivação para a criação dos blogs. A blogueira 02 atestou que: "Bom, eu tenho 


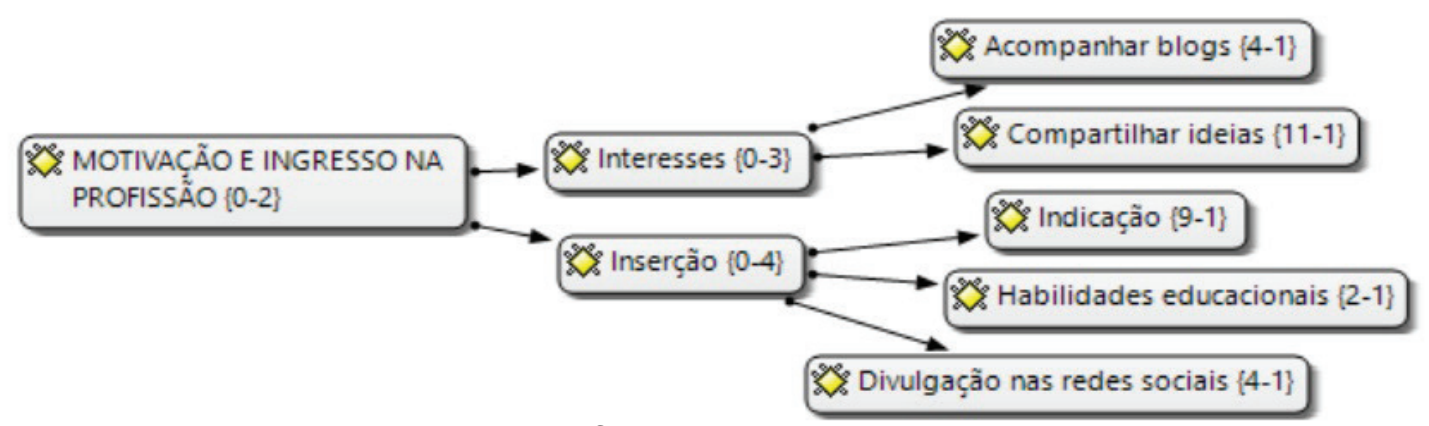

FIGURA 2 - Motivações e ingresso na profissão

Fonte: dados da pesquisa.

blog pelo menos há 10 anos, foi uma coisa bem natural". Começou quando eu precisava escrever, desabafar, na época isso era muito comum e basicamente as pessoas só criavam blogs para isso". Estes depoimentos confirmam o exposto por Chau e Xu (20I2) e Mcquarrie, Miller e Phillips (20I2), já que os blogs foram criados a partir do interesse em compartilhar suas ideias e vivências, opiniões e emoções.

No que diz respeito à inserção na profissão, nove entrevistadas ressaltaram que iniciaram o blog de forma profissional após o reconhecimento de suas habilidades, seja por elas mesmas seja por terceiros, conforme: "Após um ano compartilhando minha experiência no Instagram, o meu companheiro, que trabalha no ramo de publicidade e web design, reparou em mim um potencial e construiu minha plataforma na internet" (Blogueira II).A partir desse depoimento, também é possível perceber que atualmente os blogs já são criados como uma forma de obter rendimentos e não mais com a visão inicial de diário eletrônico. As demais participantes reforçaram que a inserção aconteceu ou por reconhecimento de habilidades educacionais que elas tinham ou por meio de divulgação nas mídias sociais.

Diante disso, pode-se ter uma visão geral de como ocorre a inserção de mulheres no ambiente de trabalho dos blogs.A seguir, analisam-se os modelos da profissão construídos pelas blogueiras, assim como o modelo idealizado que elas tinham anteriormente.

\section{Modelos da profissão}

Para o modelo idealizado, Hughes ( 1958 ; 20I5) reconhece que o senso comum traz visões estereotipadas das profissões, no qual se espera que profissionais atuem de determinada maneira, esquecendo de tratar as diferenças que ocorrem no ofício. A Figura 3 mostra uma visão das idealizações que as entrevistadas tinham sobre a profissão blogueira.

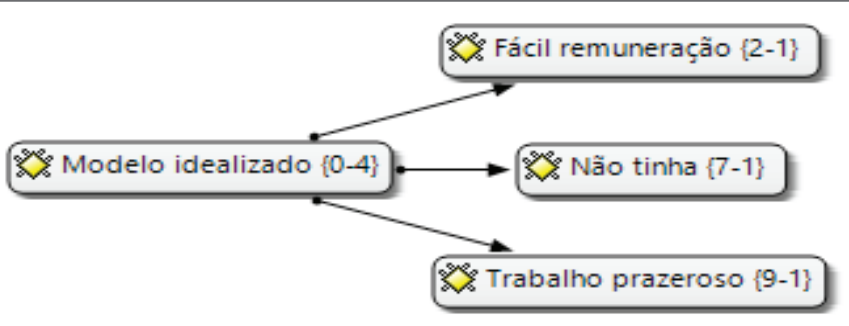

FIGURA 3 - Modelos da profissão - Idealizações

Fonte: dados da pesquisa. 
Com a finalidade de compreender o modelo idealizado buscou-se visualizar os estereótipos da profissão. Nove das entrevistadas associavam o trabalho com o blog como um trabalho prazeroso. No entanto, quatro afirmaram não terem um modelo, pois quando criaram seu primeiro blog ainda não era visto como profissão, apenas como passatempo.

Duas delas afirmaram que pensavam que seria um trabalho no qual elas ganhariam dinheiro facilmente, constatando-se, entretanto, o contrário. Percebeu-se que elas levam em média um ano para começarem a fechar seus primeiros contratos com marcas. Portanto, com exceção das blogueiras que afirmaram não ter um modelo idealizado, ou que não sabiam como a profissão se desenvolvia; as demais tinham algum estereótipo já formado em relação ao ofício de blogueira.

Para Dubar (2005) e Hughes (1958; 2015), o modelo real é aquele em que o sujeito encontra quando está imerso na prática da profissão.Assim, no modelo real, as blogueiras ressaltaram que blogs são plataformas de criação de conteúdo que têm como objetivo trazer informações aos leitores, sendo também um trabalho com muitas atividades para se executar, necessitando que elas fiquem conectadas às redes sociais 24 horas por dia (Figura 4).

Dubar (2005) define profissão (ofício), que pode ser assalariada ou não, como o reconhecimento dos modos do trabalho e habilidades técnicas; portanto, para que se tenha um maior aprofundamento de como se constitui esse modelo real, buscou-se compreender como acontece a instalação dessa dualidade - modelo real e idealizado - por meio da compreensão das habilidades que as entrevistadas julgavam ser necessárias para a realização de suas tarefas, da apreensão das tensões e frustrações vividas pelas blogueiras, das tarefas incômodas realizadas e das dificuldades que tiveram durante a realização de suas tarefas (Figura 5).

A partir das vivências das entrevistadas, buscou-se perceber quais as habilidades necessárias para o desempenho do trabaIho com blogs (Figura 6).

Primeiramente, constatou-se ser necessário ter experiências de vida significativas para compartilhar com os leitores. Isso confirma o afirmado por Herring et al. (2004) e Lasater-Wille (20I8), os quais denotam que, nas profissões com atividades mais técnicas, é mais importante as vivências do que as credenciais formais, como a formação acadêmica.

As blogueiras afirmaram ser necessário, também, ter habilidades técnicas como sa-

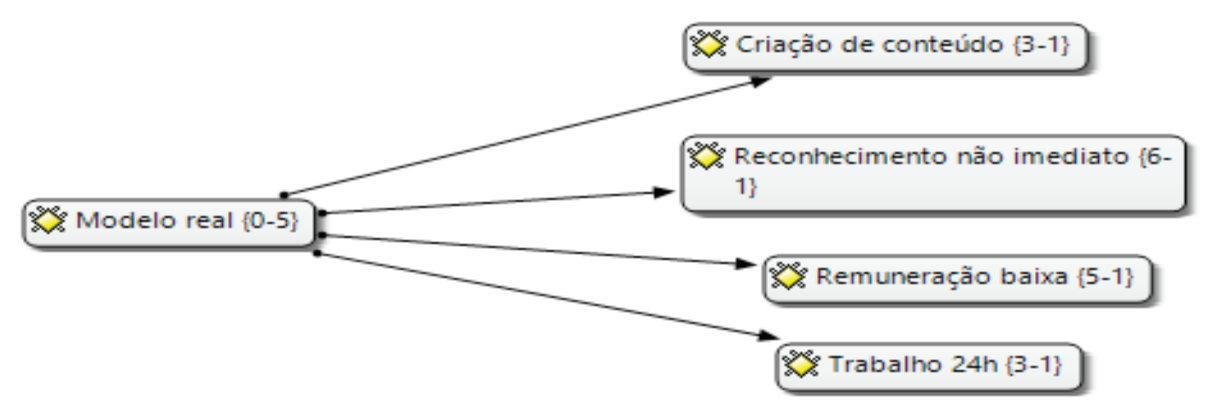

FIGURA 4 - Modelos da profissão - Realidades

Fonte: dados da pesquisa. 


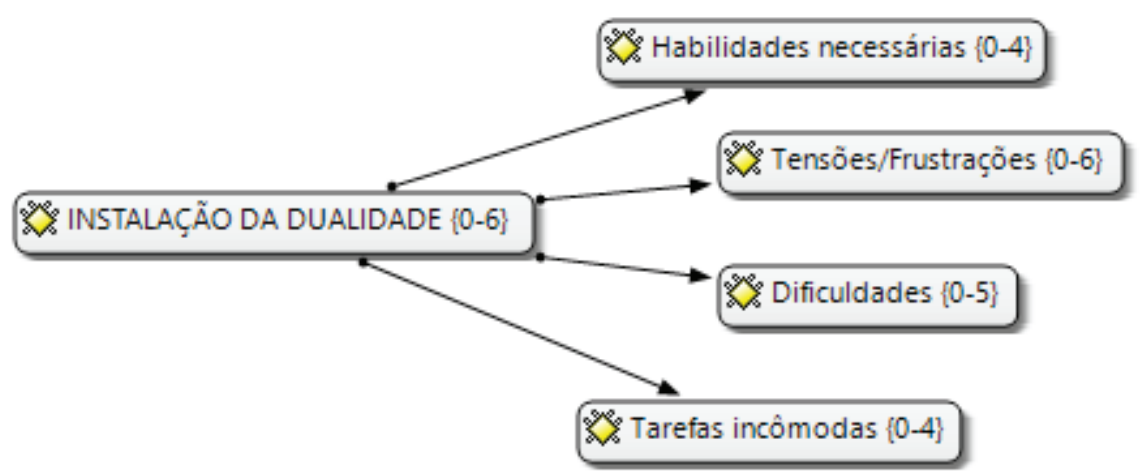

FIGURA 5 - Instalação da dualidade

Fonte: dados da pesquisa.

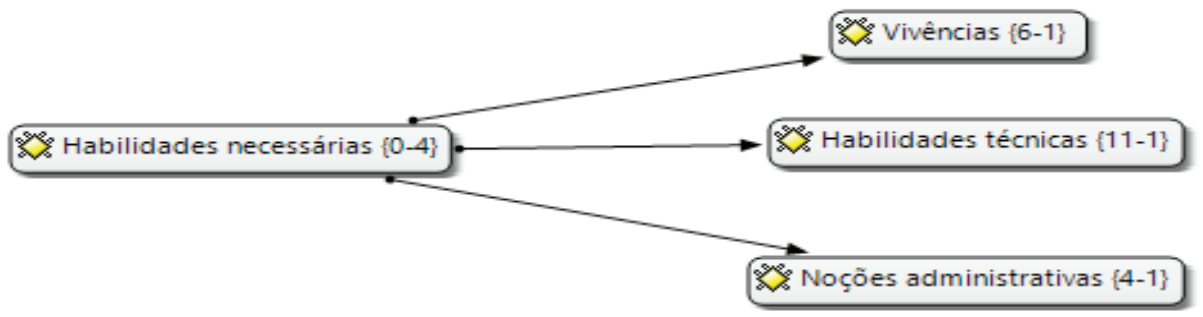

FIGURA 6 - Instalação da dualidade - Habilidades necessárias

Fonte: dados da pesquisa.

ber desenvolver sites, edição de fotografias e vídeos. Além disso, é necessário ter noções de administração para as negociações com as marcas, pensar em posicionamento do blog e outras atividades de cunho administrativo. Sobre as atividades inerentes ao blog: “...fotografar os produtos, tratar as imagens, escrever o post, agendar para o dia que vai sair, preparar a divulgação dele nas redes sociais quando for ao ar, responder os e-mails dos parceiros, enviar orçamentos com mídiakit, [...] responder os comentários do blog, preparar anúncios do blog pra divulgar, emitir nota fiscal para os clientes, cuidar da parte financeira, digamos assim" (Blogueira 02).

Dubar (2005) e Seron et al. (2016) evidenciam que para que um ofício seja considerado profissão é necessário que haja uma escolarização formal, sendo também necessário conhecimentos técnicos e vivências. Diante disso, é reconhecido de que as realidades vivenciadas durante a profissão podem causar frustrações no profissional e limitar sua capacidade para aprender habilidades e papéis (HUGHES, 1958; 20I5). Para isso, apreendeu-se as tensões vivenciadas durante a execução de seus trabalhos, como pode ser observado na Figura 7.

As tensões vivenciadas no trabalho são o acúmulo de atividades, para aquelas que tem outra atividade profissional, a visão estereotipada que a sociedade tem das blogueiras, a falta de remuneração e a visão que algumas marcas têm de permuta como remuneração para o trabalho que elas desempenham. Constatou-se, portanto, que 


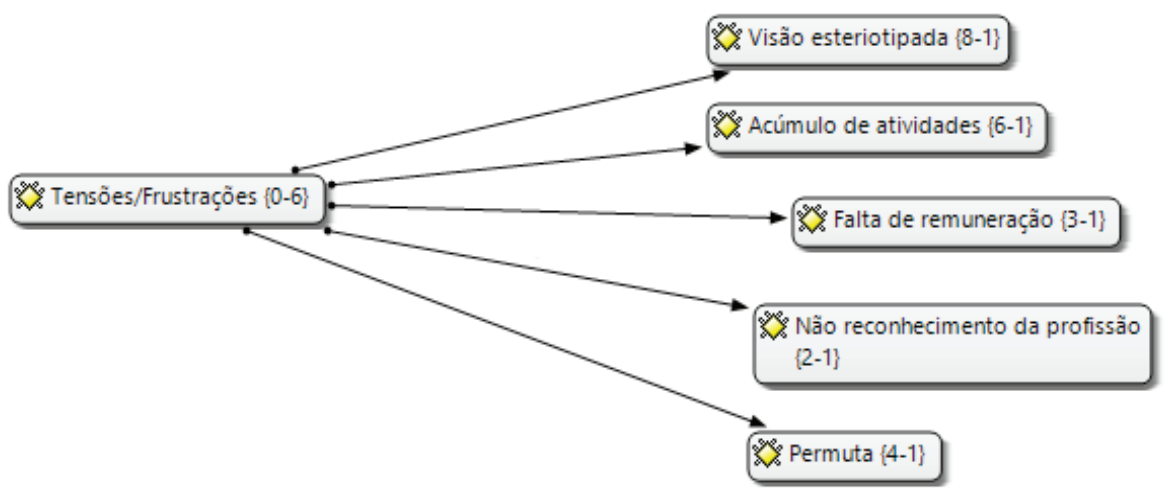

FIGURA 7 - Instalação da dualidade - Tensões/Frustrações

Fonte: dados da pesquisa.

as tensões vivenciadas limitam o aprendizado na profissão, fazendo com que algumas blogueiras cogitassem desistir das atividades com o blog para se dedicarem a outras atividades profissionais.

As dificuldades apresentadas pelas blogueiras envolviam tanto a questão de manterem seu público interessado, já que atualmente o público está preferindo mídias tenham imagem e movimento como - Youtube e o Instagram, quanto questões que se referiam a elas serem precariamen- te remuneradas. Duas entrevistadas ainda afirmaram terem dificuldades em lidar com comentários de leitores que tinham por objetivo diminuir tanto seu trabalho, quanto sua imagem (Figura 8).

A última unidade de contexto a ser analisada se refere às tarefas incômodas da profissão, conforme observa-se pela Figura 9.

Hughes $(1958 ; 2015)$ afirma que durante o trabalho algumas tarefas podem ser consideradas incômodas e impositivas. Diante dessa afirmação foi reconhecido, nos discur-

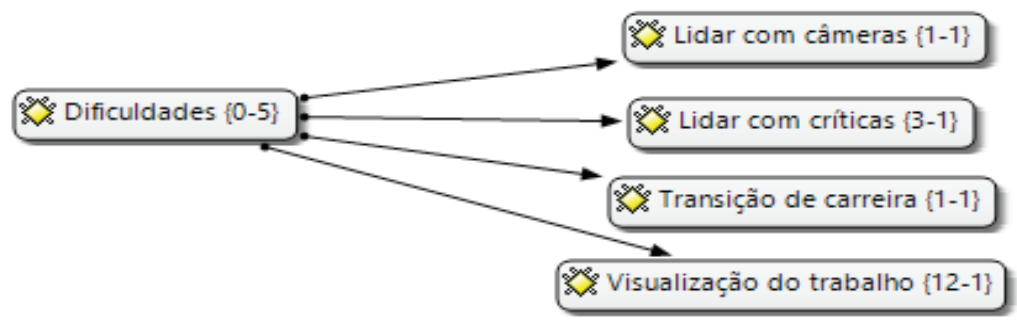

FIGURA 8 - Instalação da dualidade - Dificuldades

Fonte: dados da pesquisa.

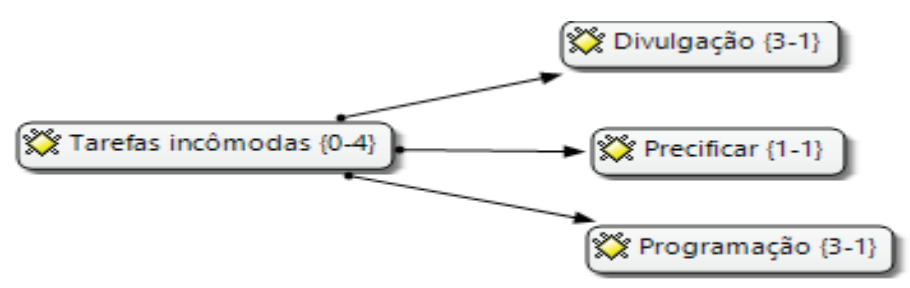

FIGURA 9 - Instalação da dualidade - Tarefas incômodas

Fonte: dados da pesquisa. 
sos das entrevistadas, que a profissão também tem suas tarefas incômodas, são elas: a precificação do trabalho; os trabalhos de ordem técnica, como edição e programação; e a divulgação do conteúdo nas redes sociais. Duas blogueiras afirmaram que uma das tensões que vivenciam e continuam vivenciando se refere ao fato de o trabalho com blogs ainda não ser visto como profissão e por isso os familiares e as outras pessoas não percebem o trabalho como algo sério. Verificando-se que, assim como todas as profissões, o trabalho com blogs também tem atividades ditas incômodas.

A dualidade do trabalho com blogs pode ser descrita a partir da imagem que esse ofício tem de aparentar ser algo glamouroso, sem muitas preocupações, e o fato de que, ao contrário, elas trabalham muito, ganham pouco e demoram a ter reconhecimento no trabalho que desenvolvem.

\section{Percepções sobre a profissão}

Para compreender como acontece a carreira dentro de uma profissão e a evolução destes profissionais é preciso identificar as linhas de carreira com base nas fases significativas de carreiras e as sequências em que ocorrem (HUGHES, 1958; 2015). Primeiramente, são analisadas as fases significativas, para então identificar as linhas de carreira; por fim, verificam-se as possí- veis mudanças na identidade das entrevistadas (Figura 10).

Observou-se que ocorrem três fases significativas sequenciais durante a carreira no trabalho com os blogs. A primeira fase é o reconhecimento trabalho realizado, seja pelas leitoras seja pela possibilidade de conhecer novas pessoas. Assim como pode ser visto no depoimento:"Criamos laços e podemos mudar muito o dia a dia de alguém pelas redes sociais. É bacana compartilhar o que nos faz sorrir. Melhor ainda é saber que a internet aproxima e dá essa chance. Cada comentário é a maior motivação para continuar" (Blogueira I0).

A segunda fase significativa que elas mencionam acontece logo após terem o seu trabalho reconhecido por marcas com as quais elas formam parcerias, como pode ser observado no depoimento: "Com certeza são as pessoas que eu conheci. $O$ contato com grandes marcas que você sempre foi fã é uma das coisas mais incríveis de ser blogueira.Acho que experiência com a Coca-Cola e a Natura foram algumas das mais legais que pude vivenciar" (Blogueira 02).

As blogueiras reforçam o fato que viajar para divulgar o trabalho com o blog é uma experiência que as marcou muito. Assim como pode ser comprovado no depoimento:"Praticamente todas as viagens que fiz na vida são resultado do trabalho com o blog,

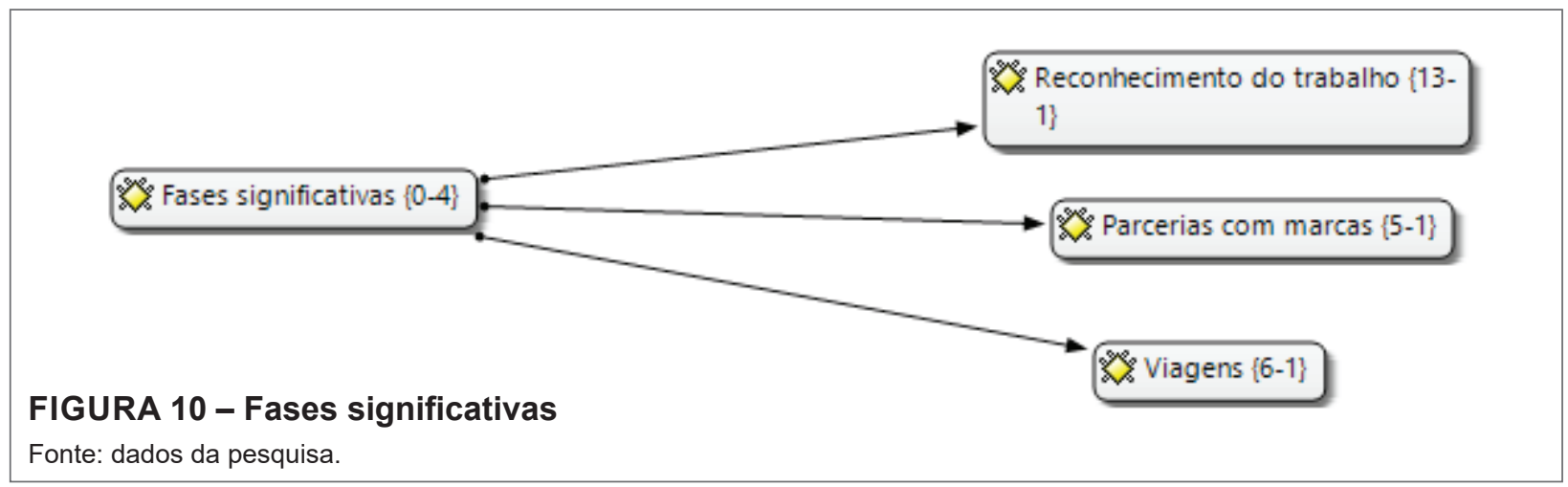


sendo elas para divulgar alguma marca ou a passeio. Também só tenho uma empresa consolidada e uma equipe que trabalha comigo por causa do blog" (Blogueira 03).

Hughes $(1958 ; 2015)$ ressalta que os trabalhos têm suas fases significativas mais ou menos claras, assim como o ofício com blog. Portanto, baseado nas fases significativas da profissão e no depoimento das entrevistadas, identificou-se as linhas de carreira possíveis (Figura II).

Algumas blogueiras ressaltaram que iniciaram seus blogs devido a necessidade de terem um passatempo. Essa é a primeira linha de carreira identificada e pode ser considerada a mais baixa na hierarquia, pois não fornece renda regular, assim como destacado do depoimento:"Mas claro que nunca tinha visto isso como profissão, e na verdade, ainda não vejo, pois, além de não ter renda com o blog, enxergo ele como meu espaço de lazer, um hobby" (Blogueira 08).

A segunda linha de carreira identificada é quando a blogueira tem renda de forma regular com o blog, mas ainda não é suficiente para se manterem somente com essa renda. Com isso, cumprem uma dupla jornada de trabalho, tendo um trabalho formal além das atividades do blog.

Por último, a dedicação exclusiva, em que a blogueira se sustenta somente com a remuneração do trabalho com mídias sociais: "[o blog] mudou totalmente minha vida inteira e minha perspectiva para o fu- turo, abandonei uma faculdade no $8^{\circ}$ período para me dedicar ao blog e ao canal no YouTube, mudou meu padrão de vida, me fez sair da minha cidade e me mudar para Uberlândia. Tudo que conquistei até hoje é fruto do hobby que se tornou meu trabaIho" (Blogueira 03).

A partir de uma mudança de responsabilidade para outra, um papel para outro faz com que o profissional sofra também mudanças na sua identidade. Em cada linha de carreira há muitos pontos positivos e negativos. Há o momento de decidir quando mudar de um trabalho para outro.Todos esses pontos são essenciais na ponderação da carreira e do crescimento e desenvolvimento da identidade profissional (HUGHES, 1958; 2015; SCHEIN, 1996). Assim, observam-se ajustes na identidade social e profissional das blogueiras (Figura 12).

As mudanças vistas pelas entrevistas em suas identidades diziam respeito a manter um equilíbrio entre a imagem pública e privada, para que seus leitores soubessem diferenciar a pessoa individual da personalidade blogueira. Duas blogueiras afirmaram que o blog as ajudou a escolher uma profissão para além do blog. Também, foi possível perceber os ajustes ocorridos na identidade das blogueiras, tornando-as pessoas mais confiantes tanto em identidade social quanto na profissional, assim como observado no depoimento:"Hoje sou uma pessoa que me comprometo melhor com

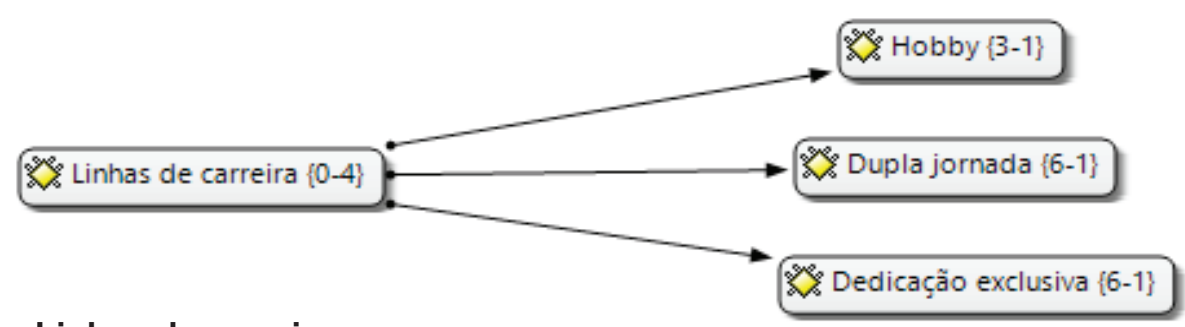

FIGURA 11 - Linhas de carreira

Fonte: dados da pesquisa. 


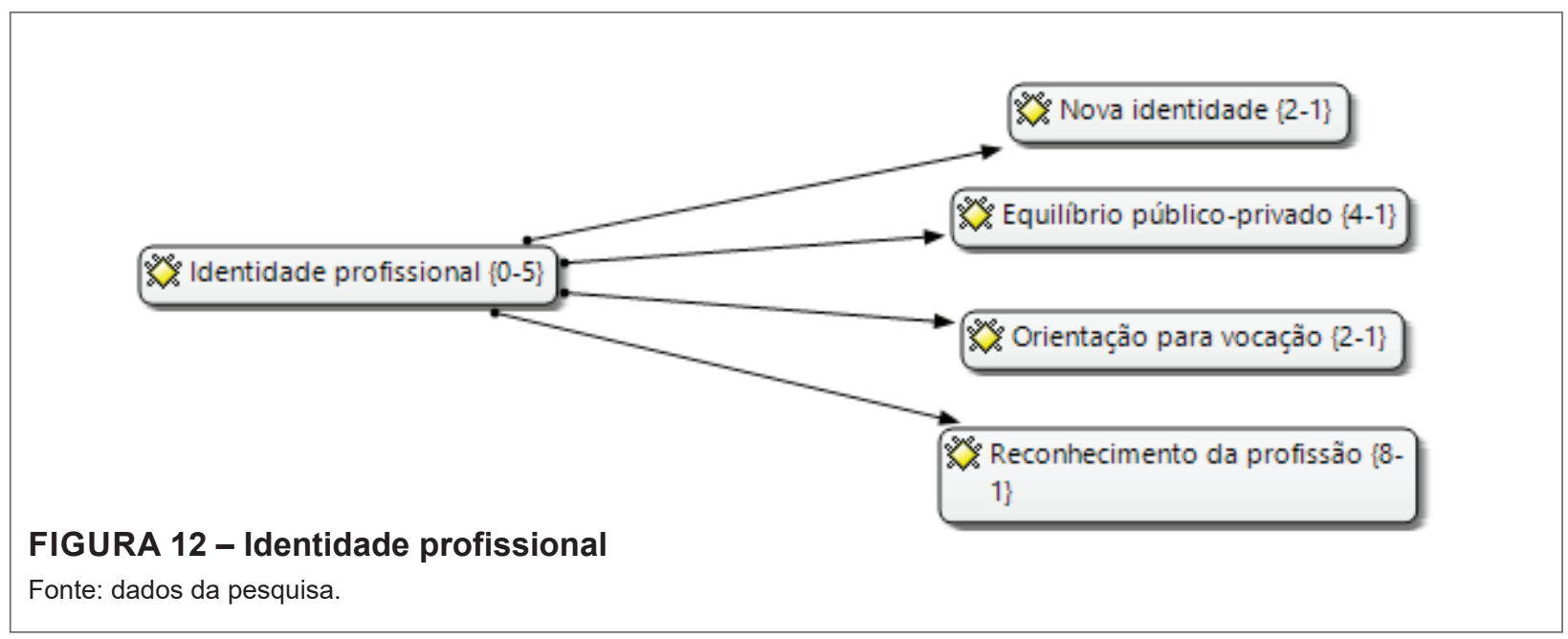

minhas atividades, gosto de me cuidar mais, busco fazer contatos com pessoas do meio e passei a ver que as celebridades têm uma vida que muitas vezes não é fácil, com muitos compromissos e obrigações. Muitas vezes julgamos as pessoas sem conhecer a realidade delas, apenas olhando fotos de revistas e redes sociais e por trás há muito trabalho" (Blogueira 09).

O depoimento da blogueira 09 reforça - que Nogueira, Ferreira e Arruda Filho (20l8) afirmam sobre a comparação das atividades executadas por celebridades. Logo, verificou-se que a atividade com blogs tem suas fases e linhas de carreira mais ou menos institucionalizadas e que essas ajudam a moldar a identidade profissional da blogueira.

\section{Síntese dos principais resultados}

Percebe-se pelo Quadro 2 os principais resultados das entrevistas com as blogueiras, podendo-se verificar as categorias de análise que estão alinhadas aos objetivos específicos; as unidades de registro correspondentes; assim como os principais resultados encontrados em cada uma delas. Além disso, é evidenciado a quantidade de citações em cada unidade de contexto, entre parênteses, e isto é pertinente para mostrar as temáticas mais mencionadas.

Dessa forma, o Quadro 2 possibilita uma sumarização das principais motivações, idealizações, dificuldades e realidades vivenciadas pelas blogueiras, e isto corrobora com as pesquisas que vêm sendo desenvolvidas sobre a temática de blogs (CHAU; XU, 20 I2; CRESCITELLI; TAGAWA, 20I5; SILVA et al., 20I5; MCQUARRIE; MILLER; PHILLIPS, 20I2; SILVA et al., 20I5).

Ademais, mediante a quantidade de citações, em especial sobre tensões e frustrações vivenciadas durante o ofício, assim como Dubar (2005) e Hughes (1958; 20I5) afirmam, em seus estudos, a descoberta da 'realidade desencantada' pode ser um fator de interrupção da carreira ou até mesmo ainda mais excitante para o profissional, pois é evidente que a categoria modelo da profissão é a que reúne os conflitos mais incidentes, como é o caso da profissão estudada.

\section{CONSIDERAÇÕES FINAIS}

Este estudo teve como principal diretriz investigar como acontece a socialização profissional de blogueiras. Pôde-se perceber que a atividade com blogs apresenta chances profissionais, identificando-se as 
QUADRO 2 - Síntese dos principais resultados da pesquisa

\begin{tabular}{|c|c|c|}
\hline Categorias de análise & Unidades de contexto & Principais resultados \\
\hline \multirow{2}{*}{$\begin{array}{l}\text { Motivações e ingresso na profis- } \\
\text { são (32) }\end{array}$} & Interesses (16) & $\begin{array}{l}\text { Criação do blog deu-se por interesse em acompanhar } \\
\text { outros blogs; } \\
\text { necessidade de compartilhar suas ideias. }\end{array}$ \\
\hline & Inserção (16) & $\begin{array}{l}\text { Habilidades educacionais; indicação de alguém; } \\
\text { divulgação nas redes sociais. }\end{array}$ \\
\hline \multirow{6}{*}{ Modelos da profissão (101) } & Modelo idealizado (18) & $\begin{array}{l}\text { Houve uma dualidade. Algumas imaginavam que ofício ti- } \\
\text { nha fácil remuneração e era um trabalho prazeroso; outras } \\
\text { não tinham um modelo definido. }\end{array}$ \\
\hline & Modelo real (17) & $\begin{array}{l}\text { Criação de conteúdo; } \\
\text { reconhecimento não imediato do trabalho exercido; traba- } \\
\text { Iho } 24 \text { horas por dia; e remuneração baixa. }\end{array}$ \\
\hline & Habilidade necessárias (21) & $\begin{array}{l}\text { Vivências para compartilhar; noções administrativas; e } \\
\text { habilidades técnicas. }\end{array}$ \\
\hline & Frustrações/Tensões (38) & $\begin{array}{l}\text { Falta de visibilidade do trabalho; lidar com críticas nega- } \\
\text { tivas; falta de remuneração no início da carreira; visão } \\
\text { estereotipada que a sociedade tem sobre os blogueiros; } \\
\text { acúmulo de atividades; e trabalho visto como permuta. }\end{array}$ \\
\hline & Dificuldades (17) & $\begin{array}{l}\text { Lidar com câmeras e com críticas; transição de carreira; e } \\
\text { visualização do trabalho }\end{array}$ \\
\hline & Tarefas incômodas (7) & $\begin{array}{l}\text { Atividades ligadas à programação; divulgação do trabalho; } \\
\text { e precificação do trabalho. }\end{array}$ \\
\hline \multirow{3}{*}{ Percepções sobre a profissão (55) } & Fases significativas (24) & $\begin{array}{l}\text { Reconhecimento dos leitores; parcerias com marcas; e } \\
\text { viagens à trabalho com o blog. }\end{array}$ \\
\hline & Linhas de carreira (15) & $\begin{array}{l}\text { Blog como Hobby; trabalho com o blog e trabalho formal } \\
\text { (Dupla jornada); e fonte de renda exclusiva pelo blog. }\end{array}$ \\
\hline & Identidade profissional (16) & $\begin{array}{l}\text { O blog as ajudou na orientação profissional; com equilíbrio } \\
\text { da imagem público-privado; reconhecimento da profissio- } \\
\text { nal; e nova percepção sobre si. }\end{array}$ \\
\hline
\end{tabular}

Fonte: elaborado pelos autores.

carreiras possíveis e suas fases significativas (DUBAR, 2005; HUGHES, 1958; 2015).

Em relação ao primeiro objetivo específico “investigar a motivação e a inserção profissional em blogs", observou-se que as blogueiras se interessaram pela atividade, considerando o desejo de acompanhar outros blogs e compartilhar ideias. A inserção na atividade, por sua vez, ocorreu pelo reconhecimento de habilidades específicas, indicação de alguém e divulgação em redes sociais.

No que se refere ao segundo objetivo específico "verificar como a profissão é percebida por aquelas que nela se inserem, enquanto modelo idealizado e modelo real de profissão", as blogueiras destacaram que, além das habilidades técnicas e administrativas que necessitam desenvolver, o modelo idealizado se contrapôs ao modelo real da profissão, vindo à tona tensões e tarefas incômodas no dia a dia.

Por fim, no tocante ao terceiro objetivo específico "explorar as possibilidades de carreira e as mudanças de identidade 
neste ofício", ao tratar das percepções sobre a profissão, destacou-se, entre as fases significativas da atividade de blogueira, o reconhecimento dos leitores, as parcerias com as marcas e as viagens a trabalho. As entrevistadas apontaram, entre as linhas de carreira, o blog como hobby; aliado ao trabalho formal; ou como fonte de renda exclusiva. No que se refere à identidade profissional, houve o reconhecimento do trabalho, equilíbrio da imagem público-privado e uma nova percepção sobre si.

A partir dos resultados obtidos, constatou-se que todas as blogueiras passaram por um processo de reconstrução de identidade, e isto proporcionou uma valorização de si e de seu trabalho, com base não somente na necessidade que elas demonstraram de ter seu trabalho valorizado, mas também de se reconhecerem de uma forma diferente após a consolidação de seu trabalho, de sua profissão como blogueira.

Vale ressaltar que as principais mudanças percebidas na sua identidade foi entender o que elas deveriam ou não compartilhar com seus leitores, visto que foi identificado, ainda, pessoas que faziam comentários no seu blog com objetivo não de fazer uma crítica construtiva ao trabalho, mas para ofendê-las, fazendo com que elas passassem a preservar sua privacidade. $O$ que demonstrou a necessidade de trazer um maior profissionalismo ao trabalho com mídias sociais. Essa modalidade de atividade é pouco reconhecida. Nem todas as entrevistadas conseguem auferir uma fonte de renda fixa com seus blogs. Além disso, o número de entrevistadas que conseguem viver apenas de sua atuação como bloguei- ra é reduzida. Constatou-se que os blogs são empresas e que já existem cursos direcionados às atividades executadas, o que demonstra o reconhecimento de blogueiro(a) como ofício e trabalho em ascensão. Isso foi reafirmado pelo fato de já existir quem inicie seu trabalho com blog, visando um retorno financeiro.

Este estudo contribui para um melhor entendimento de como ocorre a socialização profissional de mulheres que trabalham com blogs. Ademais, fornece suporte para se intensificar a percepção de como os blogs passaram do que outrora era considerado somente um passatempo para um meio que fornece sentido e fonte de renda para quem o realiza.Academicamente, o estudo se torna relevante. Pois, além de trazer novas perspectivas sobre o trabalho com blogs, abre novas possibilidades de estudos na área de profissionalização de influenciadores digitais.

Diante de algumas limitações que não foram suplantadas, como a dificuldade de acesso às blogueiras, bem como devido ao fomento de profissões emergentes, como é o caso de influenciadoras digitais (blogueiras), novas investigações podem ser realizadas com o intuito de pesquisar o trabalho com blogs sob a perspectiva empresarial, já que as blogueiras também escreveram livros e desenvolveram linhas de produtos assinados por elas; e têm, em alguns casos, uma equipe de apoio para o desenvolvimento das atividades. Além disso, a realização de pesquisas avaliando a perspectiva masculina da profissão seria interessante, além de segmentá-las por conteúdos abordados nos blogs de forma a compará-las com os resultados deste estudo. 
BARDIN, L. Análise de conteúdo. São Paulo: Edições 70, 2008.

BERNAL, A. O. Psicologia do trabalho em um mundo globalizado: Como enfrentar o assédio psicológico e estresse no trabaIho. Porto Alegre:Artmed, 2010.

BIANCO, M. F.; COLBARI, A. I.; SILVA NETO, A. O. A categoria dos auditores fiscais da Receita Federal do Brasil: a (des) construção da identidade profissional. Cadernos EBAPE.BR, v. 8, n. 3, p. 453467, 2010.

BORGES, C. N.A nova comunicação e o advento dos digital influencers: pesquisa realizada sobre blogueiras de moda. In: Congresso de Ciências da Comunicação na Região Centro-Oeste. 2018.

BROWN, A. D. Identities and identity work in organizations. International Journal of Management Reviews, v. I7, n. I, p. 20-40, 2015. BROWNELL, S. E.; TANNER, K. D. Barriers to faculty pedagogical change: lack of training, time, incentives, and... tensions with professional identity? CBE-Life Sciences Education, v. I I, n. 4, p. 339-346, 2012.

BURGESS, J.; BRUNS, A. Abordagens e Métodos para o estudo das mídias sociais na Comunicação Política. Aurora. Revista de Arte, Mídia e Política, v. 10, n. 30, p. I29-|46, 2018.

CASTRO, I.V.; SANTOS, C. D. “O que gerencio e de quem dependo?": Determinantes da ação de blogueiros. RAC-Revista de Administração Contemporânea, v. I9, n. 4, p. 486-507, 2015.

$\mathrm{CHAU}, \mathrm{M} . ; \mathrm{XU}, \mathrm{J}$. Business intelligence in blogs: Understanding consumer interactions and communities. MIS quarterly, v. 36, n. 4, p. I|89-1216, 2012.
COLLIS, J.; HUSSEY, R. Pesquisa em administração: um guia prático para alunos de graduação e pósgraduação. $2^{\mathrm{a}}$ edição. Porto Alegre: Bookman, 2005.

CORRÊA JUNIOR, J.; SOUZA NETO, S.; IZA, D. F. I. Estágio Curricular Supervisionado: lócus de socialização profi ssional, habitus e produção de saberes. Revista Brasileira de Educação Física e Esporte, v. 3I, n. I, p. I35-I52, 20 I7.

CRESCITELLI, E.; TAGAWA, Y. A influência dos blogs na decisão de compra: um estudo exploratório no segmento de beleza. Comunicação \& Sociedade, v. 37, n. 2 , p. 49-79, 2015.

DUBAR, C. A socialização: Construção das identidades sociais e profissionais. São Paulo: Martins Fontes, 2005.

ELIOT, M.; TURNS, J. Constructing professional portfolios: Sensemaking and professional identity development for engineering undergraduates. Journal of Engineering Education, v. 100, n. 4, p. 630-654, 201 I.

FREITAS, M. N. C. Organização escolar e socialização profissional de professores iniciantes. Cadernos de Pesquisa, n. II5, p. I55-I72, 2002.

FROST, H. D.; REGEHR, G. “I am a doctor": negotiating the discourses of standardization and diversity in professional identity construction. Academic Medicine, v. 88, n. 10, p. I570-I577, 2013.

HERRING, S. C.; KOUPER, I.; SCHEIDT, L. A.; WRIGHT, E. L. Women and children last: The discursive construction of weblogs. In: Into the blogosphere: Rhetoric, community, and culture of weblogs. University of Minnesota, 2004.
HUGHES, E. C. Men and their work. London: Collier-Macmillan Limited, 1958.

HUGHES, E. C. Men and their work. New Orleans: Quid Pro Books, 2015.

JACKSON, D. Developing pre-professional identity in undergraduates through work-integrated learning. Higher Education, v. 74, n. 5, p. 833-853, 2017.

LASATER-WILLE, A. Apresentação do chef na vida cotidiana: Socialização dos chefs em Lima, Peru. RAE-Revista de Administração de Empresas, v. 58, n. 3, p. 233-243, 2018.

LIMA, G. B.; NASTRI NETO, O.; CARVALHO, D. T. O papel e a importância das mídias sociais no composto de comunicação de pequenas empresas: um estudo de caso em micro-cervejaria. Revista de Administração, Contabilidade e Economia da FUNDACE, v. 4, n. I, p. I- I6, 2013.

MCQUARRIE, E. F.; MILLER, J.; PHILLIPS, B. J. The megaphone effect:Taste and audience in fashion blogging. Journal of Consumer Research, v. 40, n. I, p. I36-I58, 2012.

NASCIMENTO,T. C.; RIBEIRO,T. F.A.; CAMPOS, R. D. Oi Goxxxxxxxtosas! O Blog Boca Rosa e a Trajetória do Consumidor Produtor no Ambiente Digital, EMA - Encontro de Marketing da ANPAD. Anais... Belo Horizonte:ANPAD, p. I-3, 2016.

NOGUEIRA, C. C. V.; FERREIRA, D. O.; ARRUDA FILHO, E. J. M. A influência dos blogs de moda no processo de decisão de compra do consumidor feminino. Contextus-Revista Contemporânea de Economia e Gestão, v. I6, n. I, p. 25-54, 2018. 
OLIVEIRA, I. C.; MOREIRA NETO, A. L. C. Comportamento do consumidor: a influência das mídias sociais na decisão de compra de produtos gamers. Revista de Pós-Graduação da Faculdade Cidade Verde, v. 2, n. I, p. 3I-52, 2016.

PEDRON, C. D; SANTOS, F. M. D.; LLOBET, P. L. P. P.; CHAVES, M. S. Estratégia de relacionamento entre empresas e bloggers: o caso do setor da cosmética. Revista Base (Administração e Contabilidade) da UNISINOS, v. 12, n.2, p. II0-I2I, 2015.

PRATT, M. G.; ROCKMANN, K. W.; KAUFMANN, J. B. Constructing professional identity: The role of work and identity learning cycles in the customization of identity among medical residents. Academy of management journal, v. 49, n. 2, p. 235-262, 2006.

PRICE, S. L. Becoming a nurse: a meta-study of early professional socialization and career choice in nursing. Journal of advanced nursing, v. 65, n. I, p. I I- I9, 2009. RODRIGUES, H.A.; PAES, R. R.; SOUZA NETO, S. A socialização profissional do treinador esportivo como um processo formativo de aquisição de saberes. Movimento, v. 22, n. 2, p. 509-52I, 2016.

SANTOS, I. C. O.; LIMA, T. C. B.;
PAIVA, L. E. B.; MARQUES, D. S.; GUIMARÃES, E.T. Entre Bisturis e Desafios de Carreira: Socialização Profissional de Médicas Cirurgiãs. ENANPAD - ENCONTRO NACIONAL DOS PROGRAMAS DE PÓS-GRADUAÇÃO EM ADMINISTRAÇÃO, Anais... Curitiba: ANPAD, p. I- I6, 2018.

SCHEIN, E. H. Identidade profissional: como ajustar suas inclinações a suas opções de trabalho. São Paulo: Nobel, 1996.

SERON, C.; SILBEY, S. S.; CECH, E.; RUBINEAU, B. Persistence is cultural: Professional socialization and the reproduction of sex segregation. Work and Occupations, V. 43, n. 2, p. I78-2। 4, 2016. SHINYASHIKI, G.T.; MENDES, I.A. C.; TREVIZAN, M. A.; DAY, R. A. Socialização profissional: estudantes tornando-se enfermeiros. Revista Latino-Americana de Enfermagem, v. I4, n. 4, 2006.

SILVA, A. R. S.; LUFT, M. C. M. S. L.; ALMEIDA, A. S.; OLAVE, M. E. L. Relacionamento entre blogs de beleza e empresas de cosméticos: um estudo na perspectiva das blogueiras. Revista Gestão. Org., v. I3, p. 349-359, 2015.

SLAY, H. S.; SMITH, D. A. Professional identity construction: Using narrative to understand the negotiation of professional and stigmatized cultural identities. Human relations, v. 64, n. I, p. 85-107, 201 I.

SPUDEIT, D. F.A. O.; CUNHA, M.V. O processo de socialização na construção da identidade dos bibliotecários em Santa Catarina. Em questão, v. 22, n. 3, p. 56-85, 2016. TADIM, M. C. F., MELO, M. C. O. L., RESENDE, A. M., LOPES, A. L. M. Engenheiras Mecânicas: Configuração das Identidades Biográficas, Relacional e Sentimento de Pertença em Espaço Masculinizado.V Encontro de Gestão de Pessoas e Relações de Trabalho. Anais... Salvador:ANPAD, 2015.

TREDE, F. Role of work-integrated learning in developing professionalism and professional identity. Asia-Pacific Journal of Cooperative Education, v. I3, n. 3, p. 159-167, 2012.

TORRES, C. A Bíblia do Marketing Digital: Tudo que você queria saber sobre marketing e publicidade na internet e não tinha a quem perguntar. São Paulo: Novatec, 2009.

ZARSHENAS, L. SHARIF, F; MOLAZEM, Z.; KHAYYER, M.; ZARE, N.; EBADI, A. Professional socialization in nursing: A qualitative content analysis. Iranian journal of nursing and midwifery research, v. 19, n. 4, p. 432-438, 2014. 